\title{
microRNA expression is able to predict response to chemoradiotherapy in rectal cancer
}

\author{
MASANORI HOTCHI ${ }^{1}$, MITSUO SHIMADA ${ }^{2}$, NOBUHIRO KURITA ${ }^{2}$, TAKASHI IWATA ${ }^{2}$, HIROHIKO SATO ${ }^{2}$, \\ SHINYA MORIMOTO ${ }^{2}$, KOZO YOSHIKAWA ${ }^{2}$, JUN HIGASHIJIMA ${ }^{2}$ and TOMOHIKO MIYATANI ${ }^{2}$ \\ ${ }^{1}$ Department of Surgery, Ehime Prefectural Central Hospital, Matsuyama 790-0024; \\ ${ }^{2}$ Department of Surgery, Institute of Health Biosciences, The University of Tokushima, Tokushima 770-8503, Japan
}

Received June 14, 2012; Accepted August 2, 2012

DOI: $10.3892 / \mathrm{mco} .2012 .9$

\begin{abstract}
Although global microRNA (miRNA) expression patterns of several embryologic, physiological and oncogenic processes have been thoroughly studied, no studies are available on the role of miRNAs in pre-operative chemoradiotherapy (CRT) in rectal cancer. This study aimed to delineate the expression pattern of miRNAs for the prediction of response to CRT in rectal cancer. Rectal cancer patients $(n=43)$, who underwent pre-operative CRT (40 Gy radiotherapy combined with S-1), were studied. RNA harvested from rectal cancer biopsy specimens prior to pre-operative CRT was hybridized to miRNA microarrays (821 genes). The response to CRT was evaluated by histopathological examination of surgically resected specimens, Response Evaluation Criteria in Solid Tumors (RECIST) and downstaging. The data of miRNA microarray were evaluated by real-time reverse transcription-polymerase chain reaction (RT-PCR). Two miRNAs (miR-142-3p, 223) with an increased expression that correctly differentiated responders from non-responders to CRT were identified by histopathological examination. One gene (miR-223) showed a higher, while 8 genes (miR-20b, miR-92a, let-7a*, miR-20a, miR-17*, miR-106a, miR-17 and miR-20a*) a lower expression in responders compared to nonresponders, with regard to RECIST. The 3 genes (miR-223, miR-630 and miR-126*) had a higher expression in responders compared to non-responders, with regard to downstaging. The real-time RT-PCR evaluation analysis detected a higher miR-223 level in responders compared to non-responders. Consequently, candidate miR-223 may be a new biomarker for the prediction of response to CRT and may be useful when establishing tailor-made therapies for rectal cancer.
\end{abstract}

Correspondence to: Dr Masanori Hotchi, Department of Surgery, Ehime Prefectural Central Hospital, Kasuga 83, Matsuyama 790-0024, Japan

E-mail: mn1029keiko0524@yahoo.co.jp

Key words: tailor-made therapy, pathological response, response evaluation criteria in solid tumors, microRNA-223

\section{Introduction}

Loco-regional recurrence subsequent to rectal cancer resection is difficult to treat and is associated with severe debilitating symptoms. The prognosis after a local recurrence is poor, with a median survival period of 12-18 months (1). Pre-operative chemoradiotherapy (CRT) has been widely used as the major treatment modality to improve local control of the disease, as well as to preserve anal sphincter (2). However, response to CRT differs in tumors.

microRNAs (miRNA) are a family of small non-coding RNA molecules that downregulate the expression of their protein-coding gene targets (3). Despite the relatively small number of miRNAs, computational and experimental studies have shown that a number of human protein-coding genes are collectively regulated by miRNAs (4-6). Thus, miRNAs are considered to be master regulators of several important biological processes, such as cell growth, apoptosis, viral infection and cancer development (3,7-10). miRNA expression profiles have been shown to be promising biomarkers for the classification or outcome prediction of a wide array of human cancers $(11,12)$. While global miRNA expression patterns of several embryologic, physiologic and oncogenic processes have been thoroughly studied, no reports are available on the role of miRNAs in pre-operative CRT in rectal cancer. This is the first study using miRNA microarray for predicting response to CRT in rectal cancer. To predict response to CRT, the miRNA expression patterns of rectal cancer using miRNA microarray prior to pre-operative CRT were examined. In addition to miRNA microarray analysis, a candidate miRNA was examined using real-time reverse transcription-polymerase chain reaction (RT-PCR).

The present study aimed to define the expression patterns of miRNA for the prediction of response to CRT and to establish tailor-made therapies in rectal cancer.

\section{Materials and methods}

Patients and tissue samples. For miRNA expression profiling, rectal cancer samples were obtained from 43 patients, who were willing to receive pre-operative CRT between September 2007 and December 2009, at the Tokushima University Hospital. The 43 independent rectal tumor samples included 
Table I. Patient characteristics and response to CRT.

\begin{tabular}{|c|c|c|}
\hline Characteristics & $\begin{array}{l}\text { Training set } \\
\quad(\mathrm{n}=22)\end{array}$ & $\begin{array}{l}\text { Testing set } \\
(\mathrm{n}=21)\end{array}$ \\
\hline Male/female & $17: 5$ & $14: 7$ \\
\hline Age (years) & $72(41-82)$ & $60(44-79)$ \\
\hline Tumor size (cm) & $3.5(2.5-9.0)$ & $4.0(3.0-10.0)$ \\
\hline $\begin{array}{l}\text { Tumor distance from } \\
\text { the anal verge }(\mathrm{cm})\end{array}$ & $3.0(0-8.0)$ & $4.0(0-7.0)$ \\
\hline \multicolumn{3}{|l|}{ Grade of differentiation } \\
\hline Well/moderately & 22 & 20 \\
\hline Poorly & 0 & 1 \\
\hline \multicolumn{3}{|l|}{ Tumor stage } \\
\hline $\mathrm{T} 3$ & 20 & 19 \\
\hline $\mathrm{T} 4$ & 2 & 2 \\
\hline \multicolumn{3}{|l|}{ Nodal stage (N) } \\
\hline 0 & 8 & 11 \\
\hline 1 & 7 & 5 \\
\hline 2 & 7 & 5 \\
\hline \multicolumn{3}{|c|}{ Pathological response (grade) } \\
\hline 0 & 0 & 0 \\
\hline 1 & 7 & 9 \\
\hline 2 & 13 & 11 \\
\hline 3 & 2 & 1 \\
\hline \multicolumn{3}{|l|}{ RECIST } \\
\hline $\mathrm{CR}$ & 0 & 0 \\
\hline PR & 14 & 13 \\
\hline SD & 8 & 8 \\
\hline $\mathrm{PD}$ & 0 & 0 \\
\hline \multicolumn{3}{|l|}{ Downstaging } \\
\hline Yes & 13 & 11 \\
\hline No & 9 & 10 \\
\hline
\end{tabular}

CRT, chemoradiotherapy; RECIST, Response Evaluation Criteria in Solid Tumors; CR, complete response; PR, partial response; SD, stable disease; PD, progressive disease.

22 for training and 21 for testing the outcome prediction model, respectively. The patient characteristics and response to CRT are summarized in Table I. The study was approved by the ethics committee of the Tokushima University Hospital, while every patient provided written informed consent for their samples to be used. Biopsy specimens from rectal cancer were prospectively collected during colonoscopic examinations prior to pre-operative CRT. Parallel tumor specimens were formalin-fixed and paraffin-embedded for histologic examination, while other specimens were used for RNA extraction. Samples were used for RNA extraction when paralleled specimens contained at least 70\% tumor cells. Samples were snap-frozen immediately in liquid nitrogen and stored at $-80^{\circ} \mathrm{C}$ until RNA extraction.

The patients received CRT at a total dose of 4,000 cGy of pelvic irradiation, five times a week, with a daily fraction of
200 cGy utilizing a four-field technique. Radiation was delivered concomitantly with S-1, a novel oral fluoropyrimidine inhibitory for dihydropyrimidine dehydrogenase with a potent radiosensitizing property. The $\mathrm{S}-1$ was administered on radiation days. Surgical treatment was performed 6-8 weeks after the completion of pre-operative CRT.

miRNA microarrays. Total RNA was isolated using the miRNeasy mini kit (Qiagen, Hilden, Germany). One hundred nanograms of each RNA sample were hybridized to Agilent Human miRNA Microarray v2.0, containing 821 miRNAs (G4470B; Agilent Technologies, Inc., Santa Clara, CA, USA). miRNA labeling, hybridization and washing were carried out according to the manufacturer's instructions. Images of hybridized microarrays were obtained with a DNA microarray scanner (G2565BA; Agilent Technologies), while features were extracted using the AFE image analysis tool version A.9.5.3.1.

Real-time RT-PCR. Complementary DNA (cDNA) was synthesized from total RNA to quantify the expression levels of mature miR-223 using gene-specific primers, according to the TaqMan miRNA Assay protocol (Applied Biosystems, Carlsbad, CA, USA) in a $15 \mu 1$ reaction volume with $10 \mathrm{ng}$ of RNA template. RT was performed using the following program: $30 \mathrm{~min}$ at $16^{\circ} \mathrm{C}, 30 \mathrm{~min}$ at $42^{\circ} \mathrm{C}, 5 \mathrm{~min}$ at $85^{\circ} \mathrm{C}$ and then held at $4^{\circ} \mathrm{C}$. Reverse transcription products were diluted 20 -fold, while $2 \mu \mathrm{l}$ were used in a total reaction volume of $20 \mu \mathrm{l}$ for relative quantification by RT-PCR using an Applied Biosystems 7500 Sequence Detection system. The thermal cycling program used for quantification was as follows: $50^{\circ} \mathrm{C}$ for $2 \mathrm{~min}$ and $95^{\circ} \mathrm{C}$ for $10 \mathrm{~min}$, followed by 50 cycles of $95^{\circ} \mathrm{C}$ for $15 \mathrm{sec}$ and $60^{\circ} \mathrm{C}$ for $1 \mathrm{~min}$. Normalization was performed using the small nuclear RNA U6 (RNU6B; Applied Biosystems).

Data analysis. To identify genes that were differentially expressed in the two groups, the data sets were assigned to either responders or non-responders. Response to CRT was evaluated by three parameters [histopathological examination, Response Evaluation Criteria in Solid Tumors (RECIST) and downstaging], while miRNA microarray was analyzed in the three parameters. The histopathological examination of surgically resected specimens was based on a semi-quantitative classification system, as described in detail previously (13). Tumors were classified as responder when assigned to regression grade 2 or 3 , and non-responder when assigned to grade 0 or 1. Tumors in RECIST were classified as responder when assigned to complete response (CR) or partial response (PR), and non-responder when stable disease (SD) or progressive disease (PD). Tumors in downstaging were classified as responder when assigned to 'Yes', and non-responder when 'No'.

The samples of 43 patients were divided into a training set (22 samples) and a testing set (21 samples). In the miRNA microarray analysis to evaluate miRNA expression only training samples were used. The expression patterns were compared and the fold change value was determined to identify gene markers that best discriminated between responders and non-responders. Two-dimensional hierar- 
Table II. Frequent differentially expressed miRNAs in responders and non-responders with regard to histopathologicalal examination of surgically-resected specimens.

\begin{tabular}{lcc}
\hline microRNA & Fold change & P-value \\
\hline Overexpressed & & \\
miR-223 & 3.13 & 0.026 \\
miR-142-3p & 2.12 & 0.026 \\
\hline
\end{tabular}

Table III. Frequent differentially expressed miRNAs in responders and non-responders with regard to RECIST.

\begin{tabular}{lcc}
\hline microRNA & Fold change & P-value \\
\hline $\begin{array}{l}\text { Overexpressed } \\
\text { miR-223 }\end{array}$ & 3.13 & \\
Underexpressed & & 0.034 \\
miR-20b & 0.61 & \\
miR-92a & 0.61 & 0.048 \\
let-7a* & 0.59 & 0.024 \\
miR-20a & 0.58 & 0.048 \\
miR-17* & 0.55 & 0.041 \\
miR-106a & 0.55 & 0.012 \\
miR-17 & 0.54 & 0.024 \\
miR-20a* & 0.41 & 0.024 \\
\hline
\end{tabular}

RECIST, Response Evaluation Criteria in Solid Tumors.

chical clustering was applied to the log-transformed data with average-linkage clustering, with a standard correlation serving as the similarity metric for the discriminating genes identified as differentially expressed in responders and non-responders. Using real-time RT-PCR in a training set, a candidate miRNA detected by miRNA microarray analysis with regard to the histopathological examination of surgical specimens was evaluated. At the end. A candidate miRNA was then evaluated in a testing set using real-time RT-PCR with regard to the histopathological examination of surgical specimens.

Statistical analysis. Quantitative data were provided as the median (range). The statistical analysis was performed using statistical software (JMP 8.0.1., SAS Campus Drive, Cary, NC, USA). Comparisons of clinicopathological and PCR data were performed using the Fisher's exact, Chi-square and Mann-Whitney U tests, as appropriate. The expression patterns in the miRNA microarray were compared using unpaired t-tests (with Welch's correction for unequal variances). Receiver-operating characteristics (ROC) curves were established to evaluate the diagnostic value of candidate miRNA for differentiating between responders and non-responders. The statistical tests performed were two-sided and declared at the $5 \%$ significance level.
Table IV. Frequent differentially expressed miRNAs in responders and non-responders with regard to downstaging.

\begin{tabular}{lcc}
\hline microRNA & Fold change & P-value \\
\hline Overexpressed & & \\
miR-223 & 3.36 & 0.006 \\
miR-630 & 2.79 & 0.042 \\
miR-126* & 1.87 & 0.049 \\
\hline
\end{tabular}

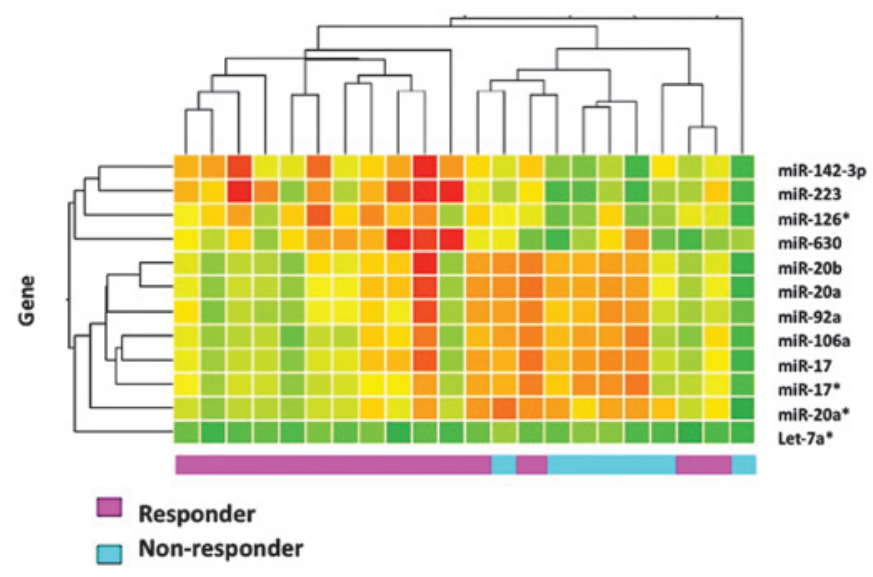

Figure 1. Hierarchical cluster analysis of the 12 miRNAs detected by three parameters is shown. Red, overexpression; green, underexpression. Pink, responders; blue, non-responders. Responders and non-responders were clustered into two distinct groups, except for four responder cases.

\section{Results}

miRNA expression patterns using microarrays in responders and non-responders. miRNA expression profiling was established using miRNA array in the training samples. No statistically significant difference was detected between the training and the testing sets with regards to clinicopathological factors, such as gender, age, histopathologicalal classification, pre-operative tumor stage and response to CRT. The patient characteristics and response to CRT are summarized in Table I. Of the 22 training samples, 15 were classified as responders and 7 as non-responders, according to the histopathologicalal examination of the surgical specimens. Initially, with regard to the histopathologicalal examination of surgically resected specimens, 2 genes differentially expressed at significant levels $(\mathrm{P}<0.05)$ in responders and non-responders (Table II) were identified. The 2 genes (miR-223 and miR-142-3p) showed a higher expression in responders compared to non-responders. Of the 22 training samples, 14 were classified as responders and 8 as non-responders, based on the RECIST. Nine genes were differentially expressed at significant levels in responders and non-responders, with regard to RECIST (Table III). One gene (miR-223) showed a higher, while 8 genes a lower expression in responders compared to non-responders. The list of underexpressed genes included miR-20b, miR-92a, let-7a*, miR-20a, miR-17*, miR-106a, miR-17 and miR-20a*. Additionally, of the 22 training samples, 13 were classified as responders and 9 as non-responders, based on downstaging. Three genes were 


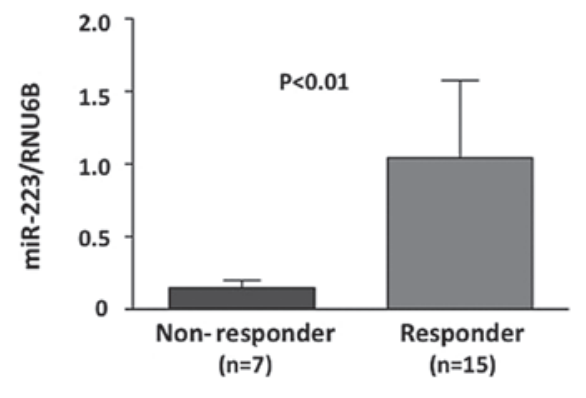

Figure 2. Evaluation of miR-223 by real-time RT-PCR in a training set is shown. Level of miR-223 showed a significantly higher expression in responders compared to non-responders, with regard to the histopathologicalal examination of surgical specimens $(\mathrm{P}<0.01)$.

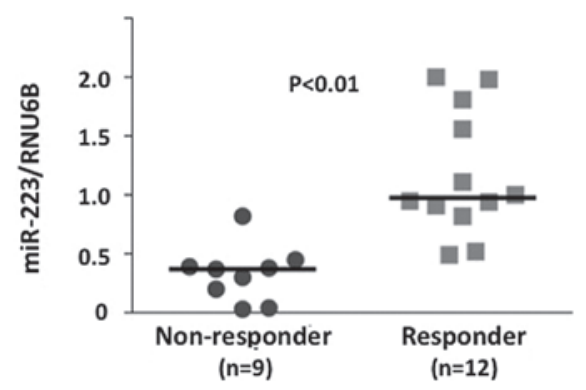

Figure 3. Evaluation of miR-223 by real-time RT-PCR in a testing set is shown. Level of miR-223 showed a higher expression in responders compared to non-responders, with regard to the histopathologicalal examination of surgical specimens $(\mathrm{P}<0.01)$.

differentially expressed at significant levels in responders and non-responders, with regard to downstaging (Table IV). The 3 genes (miR-223, miR-630 and miR-126*) showed a higher expression in responders compared to non-responders. Results of a hierarchical cluster analysis of the 12 genes detected by three parameters are shown in Fig. 1. Responders and non-responders were clustered into two distinct groups, except for four responder cases.

Evaluation of miRNA microarray data by real-time RT-PCR. miR-223, a candidate gene, showing a higher expression in responders compared to non-responders in the three parameters (histopathological examination, RECIST and downstaging) was chosen for the evaluation of miRNA microarray data using real-time RT-PCR. Initially, the miR-223 level was evaluated using real-time RT-PCR in a training set. The miR-223 level was significantly higher in responders compared to non-responders, with regard to the histopathological examination of surgical specimens $(\mathrm{P}<0.01)$ (Fig. 2). The miR-223 level in a testing set (21 independent rectal cancer samples) was evaluated. Of the 21 testing samples, 9 were classified as responders and 12 as non-responders, based on the histopathological examination of surgical specimens. The miR-223 level was higher in responders compared to non-responders $(\mathrm{P}<0.01)$ (Fig. 3). Additionally, ROC curve analyses showed that miR-223 might differentiate between responders and non-responders in 22 training samples with an area under the curve (AUC) of 0.768 [95\% confidence internal (CI), 0.661-0.865]. At the cut-off value of 0.4 for
miR-223, the sensitivity and the specificity in the 21 testing samples were 100 and $78.0 \%$, respectively (Fig. 3).

\section{Discussion}

Although miRNA expression patterns have been applied when predicting the outcome of multiple cancers, few studies have been reported as yet on the application of miRNAs when predicting the response to CRT using pre-operative biopsy tissue samples in rectal cancer. The expression patterns of miRNAs for the prediction of response to CRT by miRNA microarray were defined, while a candidate miRNA (miR-223) was evaluated by real-time RT-PCR.

In order to determine whether miR-223 showed a high or low expression when predicting the response to CRT in rectal cancer, in their study Aslam et al (14) summarized the differential expression of miRNAs in colorectal cancer compared to healthy flanking tissue identified by various studies. The results of those studies suggested that the variability of individual miRNAs with tumor type and stage probably rendered the combination of miRNAs a reliable method for detecting cancer status. In this study, the miR-223 detected as a candidate gene for the prediction of response to CRT is reported as one of the overexpressed miRNAs in colorectal cancer compared to healthy tissue $(15,16)$.

The potential value of miRNAs as prognostic and predictive biomarkers in colon cancer is demonstrated by Schetter et al (17), who compared miRNA expression patterns in stage II colonic adenocarcinoma and in adjacent healthy tissue. A high tumor:healthy expression ratio of miR-20a, miR-21, miR-106a, miR-181b and miR-203 was associated with poor survival. Underexpressed miR-20a in a tumor may be associated with good survival and responders to CRT.

Regarding the correlation between miRNAs and radiation therapy, higher rectal tumor expression levels of miR-125b and miR-137 are reported to be associated with a poorer response to CRT (18). In lung cancer and healthy lung cell lines, levels of 81 out of 440 miRNAs demonstrated statistically significant differences subsequent to irradiation with 23 miRNAs downregulated after treatment. The members of the let-7 family (except let-7g) decreased markedly by $2-8 \mathrm{~h}$ subsequent to irradiation in both cancer and healthy lung epithelium. Furthermore, let-60/RAS and genes in the DNA damage response pathway were identified as mechanisms potentially affected by let-7 (19). In addition to these results, radiotherapy of two different prostate cancer cell lines resulted in a differentiated expression of a high number of miRNAs. The expression of 48 miRNAs altered significantly subsequent to the application of radiotherapy, with 22 of them presenting a $>3$-fold change in levels. Of those 22 miRNAs hsa-miR521, hsamiR-196a and hsa-miR-133b were demonstrated to be decreased, while hsa-miR-34c was shown to be increased in the two cell lines subsequent to radiation (20). Although inconsistent with the results of the present study, the data on the let-7 family are likely to be affected by the differences in cell culture experiments and clinical research.

Different miRNAs have been found to predict sensitivity to anticancer treatment. miR-30c, miR-130a and miR-335 have been reported to be downregulated in various chemoresistant cell lines (21), while the restoration of miR-34 in p53-deficient 
human gastric cancer cells induced chemosensitisation (22). Irrelevant to the results of this study, regarding the S-1 used for CRT in the present study, Nakajima et al (23) reported that let-7g and $\mathrm{miR}-181 \mathrm{~b}$ were strongly associated with response to 5-fluorouracil-based antimetabolite S-1.

miR-223 has been reported to function as an important modulator of cellular differentiation $(24,25)$. In bone cells, the enhanced expression of pre-miR-223 completely abrogated osteoclast differentiation (25). However, few reports are available on the dysregulation of miR-223 in epithelial cancers. Although miR-223 transcription in granulopoiesis has been reported to be regulated by an evolutionarily conserved system driven by the myeloid transcription factors, PU.1 and CAAT enhancer-binding protein (26), In their study, Wong et al (27) identified stathmin 1 (STMN1) as a putative target of miR-223 in hepatocellular carcinoma (HCC). STMN1 is a key microtubuleregulatory protein that controls the microtubule dynamics, cell proliferation and S-phase of the cell cycle $(28,29)$. High-levels of STMN1 expression have been reported in leukemia, breast, ovarian and prostate cancers, in which its increased expression has been associated with increased histologic grading, shorter patient survival period and increased resistance to medication (30-33). By these mechanism, STMN1 as a putative target of miR-223, may be associated with responders to CRT.

Additionally, miR-223 has recently been found to be myeloid-specific, negatively regulating the progenitor proliferation, granulocyte differentiation and activation in mice (34). Guo et al (35) also reported that the $\mathrm{CD}_{133}{ }^{+}$ovarian cancer stem cells in the OVACAR 3 cell line were correlated with miR-223. miR-223, as a candidate miRNA to regulate stemness gene, may be associated with responders to CRT.

The present study defined the expression patterns of miRNAs for the prediction of response to CRT by miRNA microarray and evaluated miR-223 by real-time RT-PCR using pre-operative biopsy tissue samples in rectal cancer. Albeit the small samples, the lack of analysis of target mRNA, of miR-223 and functional analysis of miR-223, the expression patterns of miRNAs for the prediction of response to CRT by miRNA microarray were evaluated using several miRNAs (821 gene). Furthermore, miR-223 was evaluated by real-time RT-PCR as well as in independent samples. These results suggest that a candidate common miR-223 shown by three parameters (histopathological examination, RECIST and existence of downstaging) may be a new biomarker for the prediction of response to CRT in rectal cancer.

In conclusion, the candidate miR-223 is a potential new biomarker for the prediction of response to CRT and is likely to be useful for establishing tailor-made therapies for rectal cancer.

\section{Acknowledgements}

The present study was partly financed by the Research Support Foundation of the University of Tokushima and Taiho Pharmaceutical, Co., Ltd. (research funding provided to Professor Mitsuo Shimada), and the Grants-in-Aid for Scientific Research of the Japan Society for the Promotion of Science. A part of this study was presented at the Gastrointestinal Cancer Symposium, San Francisco, CA, USA (January 15-17, 2009).

\section{References}

1. Holm T, Cedermark B and Rutqvist LE: Local recurrence of rectal adenocarcinoma after 'curative' surgery with and without pre-operative radiotherapy. Br J Surg 81: 452-455, 1994.

2. Sauer R, Becker H, Hohenberger W, Rödel C, Wittekind C, Fietkau R, Martus P, Tschmelitsch J, Hager E, Hess CF, Karstens JH, Liersch T, Schmidberger H and Raab R; German Rectal Cancer Study Group: Pre-operative versus postoperative chemoradiotherapy for rectal cancer. N Engl J Med 351: 1731-1740, 2004.

3. Ambros V: The functions of animal microRNAs. Nature 431: 350-355, 2004

4. Lim LP, Lau NC, Garrett-Engele P, Grimson A, Schelter JM, Castle J, Bartel DP, Linsley PS and Johnson JM: Microarray analysis shows that some microRNAs downregulate large numbers of target mRNAs. Nature 433: 769-773, 2005.

5. Lewis BP, Burge CB and Bartel DP: Conserved seed pairing, often flanked by adenosines, indicates that thousands of human genes are microRNA targets. Cell 120: 15-20, 2005.

6. Miranda KC, Huynh T, Tay Y, Ang YS, Tam WL, Thomson AM, Lim B and Rigoutsos I: A pattern-based method for the identification of microRNA binding sites and their corresponding heteroduplexes. Cell 126: 1203-1217, 2006.

7. Calin GA and Croce CM: MicroRNA signatures in human cancers. Nat Rev Cancer 6: 857-866, 2006.

8. Kent OA and Mendell JT: A small piece in the cancer puzzle: microRNAs as tumor suppressors and oncogenes. Oncogene 25: 6188-6196, 2006

9. Johnson CD, Esquela-Kerscher A, Stefani G, Byrom M, Kelnar K, Ovcharenko D, Wilson M, Wang X, Shelton J, Shingara J, Chin L, Brown D and Slack FJ: The let-7 micro-RNA represses cell proliferation pathways in human cells. Cancer Res 67: 7713-7722, 2007.

10. Miska EA: How microRNAs control cell division, differentiation and death. Curr Opin Genet Dev 15: 563-568, 2005.

11. Jay C, Nemunaitis J, Chen P, Fulgham P and Tong AW: miRNA profiling for diagnosis and prognosis of human cancer. DNA Cell Biol 26: 293-300, 2007.

12. Yu SL, Chen HY, Yang PC and Chen JJ: Unique microRNA signature and clinical outcome of cancers. DNA Cell Biol 26: 283-292, 2007.

13. Japanese Society for Cancer of the Colon and Rectum: Response Assessment of Nonsurgical Treatment for Colorectal Carcinoma. Japanese classification of colorectal carcinoma. 1st English edition. Kanehara \& Co. Ltd., Tokyo, pp77-82, 1997.

14. Aslam MI, Taylor K, Pringle JH and Jameson JS: MicroRNAs are novel biomarkers of colorectal cancer. Br J Surg 96: 702-710, 2009.

15. Volinia S, Calin GA, Liu CG, Ambs S, Cimmino A, Petrocca F, Visone R, Iorio M, Roldo C, Ferracin M, Prueitt RL, Yanaihara N, Lanza G, Scarpa A, Vecchione A, Negrini M, Harris CC and Croce CM: A microRNA expression signature of human solid tumors defines cancer gene targets. Proc Natl Acad Sci USA 103: 2257-2261, 2006

16. Monzo M, Navarro A, Bandres E, Artells R, Moreno I, Gel B, Ibeas R, Moreno J, Martinez F, Diaz T, Martinez A, Balagué O and Garcia-Foncillas J: Overlapping expression of microRNAs in human embryonic colon and colorectal cancer. Cell Res 18: 823-833, 2008

17. Schetter AJ, Leung SY, Sohn JJ, Zanetti KA, Bowman ED, Yanaihara N, Yuen ST, Chan TL, Kwong DL, Au GK, Liu CG, Calin GA, Croce CM and Harris CC: MicroRNA expression profiles associated with prognosis and therapeutic outcome in colon adenocarcinoma. JAMA 299: 425-436, 2008.

18. Svoboda M, Izakovicova Holla L, Sefr R, Vrtkova I, Kocakova I, Tichy B and Dvorak J: Micro-RNAs miR125b and miR137 are frequently upregulated in response to capecitabine chemoradiotherapy of rectal cancer. Int J Oncol 33: 541-547, 2008.

19. Weidhaas JB, Babar I, Nallur SM, Trang P, Roush S, Boehm M, Gillespie E and Slack FJ: MicroRNAs as potential agents to alter resistance to cytotoxic anticancer therapy. Cancer Res 67: 11111-11116, 2007.

20. Josson S, Sung SY, Lao K, Chung LW and Johnstone PA: Radiation modulation of microRNA in prostate cancer cell lines. Prostate 68: 1599-1606, 2008.

21. Sorrentino A, Liu CG, Addario A, Peschle C, Scambia G and Ferlini C: Role of microRNAs in drug-resistant ovarian cancer cells. Gynecol Oncol 111: 478-486, 2008. 
22. Salter KH, Acharya CR, Walters KS, Redman R, Anguiano A, Garman KS, Anders CK, Mukherjee S, Dressman HK, Barry WT, Marcom KP, Olson J, Nevins JR and Potti A: An integrated approach to the prediction of chemotherapeutic response in patients with breast cancer. PLoS One 3: e1908, 2008.

23. Nakajima G, Hayashi K, Xi Y, Kudo K, Uchida K, Takasaki K, Yamamoto $\mathrm{M}$ and Ju J: Non-coding microRNAs hsa-let-7g and hsa-miR-181b are associated with chemoresponse to S-1 in colon cancer. Cancer Genom Proteom 3: 317-324, 2006.

24. Fazi F, Rosa A, Fatica A, Gelmetti V, De Marchis ML, Nervi C and Bozzoni I: A minicircuitry comprised of microRNA-223 and transcription factors NFI-A and C/EBPalpha regulates human granulopoiesis. Cell 23: 819-831, 2005.

25. Sugatani T and Hruska KA: MicroRNA-223 is a key factor in osteoclast differentiation. J Cell Biochem 101: 996-999, 2007.

26. Fukao T, Fukuda Y, Kiga K, Sharif J, Hino K, Enomoto Y, Kawamura A, Nakamura K, Takeuchi T and Tanabe M: An evolutionarily conserved mechanism for microRNA-223 expression revealed by microRNA gene profiling. Cell 129: 617-631, 2007.

27. Wong QW, Lung RW, Law PT, Lai PB, Chan KY, To KF and Wong N: MicroRNA-223 is commonly repressed in hepatocellular carcinoma and potentiates expression of Stathmin1. Gastroenterology 135: 257-269, 2008

28. Melhem RF, Strahler JR, Hailat N, Zhu XX and Hanash SM: Involvement of OP18 in cell proliferation. Biochem Biophys Res Commun 179: 1649-1655, 1991.

29. Rubin CL and Atweh GF: The role of stathmin in the regulation of the cell cycle. J Cell Biochem 93: 242-250, 2004
30. Brattsand G, Roos G, Marklund U, Ueda H, Landberg G, Nånberg $\mathrm{E}$, Sideras $\mathrm{P}$ and Gullberg $\mathrm{M}$ : Quantitative analysis of the expression and regulation of an activation-regulated phosphoprotein (oncoprotein 18) in healthy and neoplastic cells. Leukemia 7: 569-579, 1993.

31. Ghosh R, Gu G, Tillman E, Yuan J, Wang Y, Fazli L, Rennie PS and Kasper S: Increased expression and differential phosphorylation of stathmin may promote prostate cancer progression. Prostate 67: 1038-1052, 2007.

32. Alli E, Yang JM, Ford JM and Hait WN: Reversal of stathmin-mediated resistance to paclitaxel and vinblastine in human breast carcinoma cells. Mol Pharmacol 71: 1233-1240, 2007.

33. Saal LH, Johansson P, Holm K, Gruvberger-Saal SK, She QB, Maurer M, Koujak S, Ferrando AA, Malmström P, Memeo L, Isola J, Bendahl PO, Rosen N, Hibshoosh H, Ringnér M, Borg A and Parsons R: Poor prognosis in carcinoma is associated with a gene expression signature of aberrant PTEN tumor suppressor pathway activity. Proc Natl Acad Sci USA 104: 7564-7569, 2007.

34. Johnnidis JB, Harris MH, Wheeler RT, Stehling-Sun S, Lam MH, Kirak O, Brummelkamp TR, Fleming MD and Camargo FD: Regulation of progenitor cell proliferation and granulocyte function by microRNA-223. Nature 451: 1125-1129, 2008.

35. Guo R, Wu Q, Liu F and Wang Y: Description of the CD133+ subpopulation of the human ovarian cancer cell line OVCAR3. Oncol Rep 25: 141-146, 2011. 